\title{
CASO MEDELLÍN VS. TEXAS. COMENTARIOS AL FALLO DE LA SUPREMA CORTE DE LOS ESTADOS UNIDOS ASÍ COMO A LA SOLICITUD DE INTEPRETACIÓN DEL FALLO AVENA DEL 31 DE MARZO DE 2004, PRESENTADA A LA CORTE INTERNACIONAL DE JUSTICIA POR MÉXICO EN JUNIO DE 2008*
}

\section{Pablo A. ArRocha OlabUenagA**}

Resumen: En este ensayo se hace un análisis crítico de la sentencia de la Suprema Corte de los Estados Unidos de América, publicada el pasado 25 de marzo de 2008, en el caso Medellín vs. Texas, en la cual se resuelve que ni el fallo Avena de la Corte Internacional de Justicia (2004) ni el memorando del presidente George W. Bush constituyen leyes federales, por lo que las obligaciones contenidas en dichos instrumentos no son vinculantes ni ejecutables en las cortes locales estadounidenses.

ABSTRACT: This essay analyzes from a critical point of view the judgment of the United States Supreme Court in the case Medellin vs. Texas, rendered on 25 June 2008, in which the Court decides that neither the Avena judgment of the International Court of Justice, nor the memorandum issued by President George W. Bush, constitute federal laws, reason for which the obligations contained in said documents are not binding nor enforceable in United States' local courts. It also addresses the actions of Mexico following this judgment, before the International Court of Justice.

RÉSUMÉ: Dans cet essai se fait une analyse critique de la sentence de la Cour Suprême des Etats-Unis que avait publié le dernier 25 mars 2008 dans le cas Medellin v. Texas, dans laquelle se résout que ni la sentence Avena de la Court International de Justice (2004), ni le mémorandum du Présidente George W. Bush, constituent lois fédérales. Ainsi, les obligations contenues dans ces documents ne sont pas obligatoires ni exécutables dans les courts locales américaines.

* Artículo recibido el 21 de julio de 2008 y aceptado para su publicación el 8 de agosto de 2008 .

** Licenciado en derecho por la Facultad de Derecho de la UNAM. 
Sumario: I. Introducción. II. Caso Avena. III. Sentencia Medellin vs. Texas. IV. Solicitud de interpretación del fallo Ave$n a$. V. Reflexiones finales sobre la sentencia Medellín vs. Texas y la ejecución de José Ernesto Medellín. VI. Conclusión.

VII. Anexo.

\section{INTRODUCCIÓN}

José Ernesto Medellín Rojas, oriundo de Nuevo Laredo, Tamaulipas, fue arrestado el 29 de junio de 1993 como responsable del homicidio, secuestro y violación de las menores Jennifer Ertman y Elizabeth Peña, de 14 y 16 años de edad, respectivamente, hechos que ocurrieron el 24 de junio de 1993. Al momento de su arresto, los oficiales estadounidenses le informaron de sus derechos a través de la famosa fórmula Miranda. Sin embargo, no informaron a Medellín de su derecho a contactar al consulado mexicano, de conformidad con la Convención de Viena sobre Relaciones Consulares de 1963.

José Ernesto Medellín fue sentenciado a muerte el 21 de octubre de 1994 por la Corte de Distrito del Condado de Harris, en Houston, Texas.

Dicha decisión fue atacada; la Corte Criminal de Apelaciones del Estado de Texas, en Austin, designó al licenciado Randy McDonalds para el proceso de apelación directa a la sentencia impuesta. Dicha sentencia fue confirmada por la Corte Criminal de Apelaciones el 16 de mayo de $1997 .{ }^{1}$

Medellín hizo valer el argumento de la violación a sus derechos consulares por primera vez en su recurso de reparación judicial (postconviction relief). Dicho recurso fue desechado por la corte estatal con base en la doctrina de la "preclusión procesal" (procedural default doctrine). La preclusión procesal se refiere a la caducidad de una acción por no haberla interpuesto en el momento procesal oportuno. Así, la Corte de Texas resolvió que dicho recurso se debió hacer valer tanto en el juicio principal como en la revisión, cosa que no sucedió. Por lo tanto, el momento procesal oportuno para reclamar derechos consulares había caducado. ${ }^{2}$

Posteriormente, Medellín interpuso un recurso de habeas corpus ante una Corte Federal de Distrito, la cual confirmó que el derecho de recla-

1 Medellín vs. State, núm. 71,997 (Tex. Crim. App., May 16, 1997).

2 Ibidem, pp. 62, 64 y 65. 
mar violaciones a la Convención de Viena había ya precluido. Además, dijo, Medellín había fallado en demostrar cómo la violación a sus derechos consulares causaba un perjuicio directo a su causa. ${ }^{3}$

En tanto Medellín esperaba respuesta de la Corte Federal de Apelaciones del Quinto Circuito, con sede en Nueva Orleáns, sobre su certificado de apelación, el 31 de marzo de 2004 la Corte Internacional de Justicia emitió su sentencia en el caso relativo a Avena y otros nacionales mexicanos. ${ }^{4}$ En ella, el máximo tribunal internacional resolvió que los Estados Unidos de América habían violado el artículo 36 de la Convención de Viena sobre Relaciones Consulares al no notificar a 52 mexicanos de su derecho a contactar a su consulado, así como por no haber notificado a México de la detención de sus nacionales. Entre los 52 nacionales mexicanos a los que aplicaba el fallo Avena se encontraba José Ernesto Medellín.

No obstante lo anterior, la Corte Federal de Apelaciones del Quinto Circuito denegó el recurso de apelación al concluir que la Convención de Viena de 1963 no otorgaba derechos de los que los individuos pudiesen ser titulares. ${ }^{5}$

En consecuencia, Medellín interpuso el recurso de certiorari ante la Suprema Corte de Justicia de los Estados Unidos, el cual fue admitido en $2005 .{ }^{6}$ Por su parte, el 28 de febrero de ese mismo año el presidente George W. Bush emitió un memorando en el que establecía que el fallo Avena era vinculante para las cortes estatales. Dicho memorando fue presentado mediante un escrito del gobierno estadounidense como amicus curiae. ${ }^{7}$ La Suprema Corte devolvió entonces el expediente a la Corte de Apelaciones de Texas, ante la cual Medellín hizo valer un segundo recurso de habeas corpus en el que se solicitaba la revisión y reconsideración de su caso, de conformidad con lo ordenado por la Corte Interna-

3 Medellín vs. Cockrell, Civ. Action no. H-01-4078 (SD Tex., June 26, 2003).

4 Case Concerning Avena and Other Mexican Nationals (Mexico vs. United States of America) Judgment, ICJ Rep. 2004, p. 12.

5 Medellín vs. Dretke, 371 F. 3d 270, 281 (2004).

6 Medellín vs. Dretke, 544 US 660, 661 (2005) (per curiam) (Medellín I).

7 Br. for US as Amicus Curiae Supporting Resp't at App. 2, Medellin vs. Dretke, 544 US 660 (2005) (Núm. 04-5928). 
cional de Justicia. ${ }^{8}$ La Corte de Apelaciones de Texas volvió a negar el recurso interpuesto ante ella, considerándolo un abuso de orden judicial. ${ }^{9}$

Un nuevo recurso de certiorari fue presentado ante la Suprema Corte. Ésta resolvió el 25 de marzo de 2008 que las cortes estadounidenses, y en particular la Corte del estado de Texas, no están obligadas a cumplir con las decisiones de la Corte Internacional de Justicia; se requiere un proceso legislativo a fin de incorporar tales decisiones al orden interno de la unión americana. ${ }^{10}$

De esta manera, la revisión y reconsideración ordenada por la Corte Internacional de Justicia fue negada en definitiva. En consecuencia, el 5 de mayo de 2008 la Corte de Texas fijó fecha de ejecución para José Ernesto Medellín: el 5 de agosto de 2008.

\section{CASO AVENA ${ }^{11}$}

Después de la publicación de la sentencia de la Corte Internacional de Justicia sobre el caso Avena el 31 de marzo de 2004, el embajador Juan Manuel Gómez-Robledo, quien fuese agente de México en el caso, escribió un artículo en esta misma publicación en donde se analiza y se resume de manera muy completa y puntual el fallo en comento. ${ }^{12}$

No pretendemos, pues, repetir sus palabras ni volver a elaborar tal análisis aquí. Sin embargo, vale la pena enfatizar ciertos pasajes de la sentencia de la Corte para entender con claridad la disputa institucional que ésta ha generado cuatro años más tarde.

Por lo que hace a los hechos, podemos decir lo siguiente:

8 Ex parte Medellín, 223 SW 3d 315, 322-323 (Tex. Crim. App. 2006).

9 Ibidem, p. 352.

10 Medellín vs. Texas, 128 S. Ct. 1346 (US 2008) (Núm. 06-984).

11 Cabe mencionar que a la fecha no existe una traducción oficial del caso al idioma español. Si el lector desea acceder a una reseña en este idioma, sugerimos la lectura de la misma contenida en la obra Los nuevos desarrollos del derecho internacional público, de la autoría del embajador Hermilo López-Bassols (3a. ed., México, Porrúa, 2008, pp. 534-544), la cual a nuestro juicio contiene una clara descripción de los elementos jurídicos más relevantes atendidos por la Corte.

12 Gómez-Robledo Verduzco, Juan Manuel, "El caso Avena y otros nacionales mexicanos (México c. Estados Unidos de América) ante la Corte Internacional de Justicia", Anuario Mexicano de Derecho Internacional, México, vol. V, 2005, pp. 173-220. 
Para 2003, cincuenta y cuatro nacionales mexicanos habían sido detenidos y enjuiciados en los Estados Unidos por crímenes cometidos en ese país; todos ellos fueron condenados a la pena capital. Cabe mencionar que aun cuando la demanda de México se presentó en favor de estos cincuenta y cuatro casos, dos fueron retirados de la demanda - Enrique Zambrano y Pedro Hernández - a solicitud del gobierno de México el 28 de noviembre de 2003.

El estatus respecto de los cincuenta y dos casos era el siguiente: los procesos penales se habían sustanciado en nueve estados de la unión americana (28 casos en California, 15 casos en Texas, tres casos en Illinois, y uno en Arizona, Arkansas, Nevada, Ohio, Oklahoma y Oregon, respectivamente).

México sostuvo ante la Corte Internacional de Justicia que cincuenta de sus nacionales detenidos no fueron informados por las autoridades estadounidenses competentes de sus derechos, de conformidad con el artículo 36 de la Convención de Viena sobre Relaciones Consulares, y que en los otros dos casos los detenidos no fueron informados sin dilación por parte de las autoridades estadounidenses de sus derechos consulares. México, por su parte, tuvo conocimiento de la detención de veintinueve nacionales una vez que éstos ya tenían sentencia en su contra, mientras que en los veintitrés casos restantes México se enteró de las detenciones por medios distintos a la notificación consular.

En lo que respecta al agotamiento de recursos internos, de los cincuenta y dos casos presentados, veinticuatro se encontraban en apelación directa; en veinticinco casos se había concluido dicha apelación sin haber obtenido resultados favorables, y en consecuencia se había promovido el recurso de habeas corpus en esos casos; finalmente, en tres casos más ya no había otro recurso que pudiese ser agotado. ${ }^{13}$

Respecto al fondo del caso, es necesario abordar el pronunciamiento de la Corte respecto a la llamada doctrina de la preclusión procesal. Dicha doctrina tiene una relevancia particular en este caso por un motivo que ya fue señalado en la introducción de este trabajo: la Corte Criminal de Apelaciones de Texas desechó el recurso de habeas corpus presentado por Medellín con base en la doctrina antes citada. A pesar de haberse

13 Véase Case Concerning Avena and Other Mexican Nationals (Mexico vs. Unites States of America) (Memorial of Mexico), 20 June 2003, publicado en http://www.icj-cij. org/docket/files/128/8272.pdf. 
publicado ya para ese momento el fallo Avena, la Suprema Corte de los Estados Unidos confirmó tal decisión de Texas como válida en el recurso de certiorari interpuesto por Medellín.

La Corte aceptó la siguiente definición ofrecida por México sobre la doctrina de la preclusión procesal, toda vez que ésta no fue objetada por los Estados Unidos: por el hecho de que la parte defensora pudiese haber presentado un recurso legal en el juicio, pero deja de hacerlo, generalmente habrá perdido el derecho de interponer dicho recurso en algún momento posterior del proceso judicial, ya sea apelación o en el recurso de habeas corpus. ${ }^{14}$

A continuación la Corte reiteró que este asunto ya había sido analizado en el caso LaGrand, en donde había establecido que la doctrina de la preclusión procesal per se no es violatoria del artículo 36 de la Convención de Viena sobre Relaciones Consulares, pero que en aquellos casos en los que la aplicación de la doctrina impidiese que el detenido pudiera presentar una queja en contra de una acusación o sentencia argumentando que las autoridades del Estado receptor fallaron en informarle sin dilación de sus derechos consulares y que, por lo tanto, no interpuso el recurso debido por falta de la asistencia que le pudo haber brindado su consulado, dicha doctrina resultaría inaplicable. ${ }^{15}$

En otras palabras, cuando se viola el artículo 36 de la Convención de Viena por falta de una expedita notificación consular, el detenido deja de tener recursos efectivos a su alcance para combatir una sentencia o un cargo en su contra. ${ }^{16}$ Tal fue el caso de José Ernesto Medellín.

La aplicación de la doctrina de la preclusión procesal, cuando se han violado los derechos consulares de un detenido, tiene un impacto directo en la reparación que deba ser ordenada. La causalidad es evidente: la falta de notificación consular impide la interposición de recursos de defensa en el debido tiempo y en la debida forma; ello conlleva el que la defensa no pueda hacer valer recursos efectivos en favor del detenido, lo que implica una clara violación al debido proceso (como lo dijo la Corte Inte-

14 Case Concerning Avena and Other Mexican Nationals (Mexico vs. Unites States of America) Judgment, ICJ Rep. 2004, para. 111.

15 Ibidem, para. 112.

16 Ibidem, para. 134. 
ramericana en la OC-16); ${ }^{17}$ en consecuencia, la reparación debe subsanar dichas violaciones al debido proceso penal sustanciado en contra de los detenidos.

No obstante lo anterior, es entendible que la Corte Internacional de Justicia no pueda (ni deba) ordenar que todo lo actuado en las cortes penales de la unión americana en contra de los cincuenta y dos mexicanos detenidos, a quienes se les violaron sus derechos consulares, deba considerarse nulo y sin efectos. Existen dos argumentos claros al respecto: el primero se refiere al principio general de derecho internacional conocido como la no intervención en asuntos internos del Estado. Si la Corte ordenase la eliminación de cincuenta y dos procesos penales en Estados Unidos se estaría violentando el orden jurídico interno estadounidense al poner en tela de juicio la validez de dichos procesos. Además, la Corte Internacional de Justicia, en ese caso, se estaría erigiendo como corte de "tercera instancia" en los procesos penales, cosa que resulta a todas luces inadmisible. En este sentido, resulta relevante repetir aquí lo que la Corte asentó en su fallo: este caso concierne a la aplicación del artículo 36 de la Convención de Viena sobre Relaciones Consulares y, en consecuencia, no busca analizar los procesos penales internos a fin de determinar si éstos han sido sustanciados correctamente. ${ }^{18}$

El segundo argumento atiende a la falta de claridad respecto del perjuicio directo causado al detenido en el caso particular. Pues si bien en cincuenta y dos casos Estados Unidos violó el derecho de notificación consular de los mexicanos detenidos y sentenciados a muerte, ello nada sugiere respecto al impacto que tal violación pudiese tener en cada uno de los cincuenta y dos casos. Mientras que en uno la interposición de un recurso en particular puede resultar en la conmutación de la pena impuesta, en otro los recursos que pudiesen ser interpuestos podrían ser válidamente desechados por las cortes penales locales con base en fundamentos jurídicos relativos a la ley penal aplicable. El caso Avena no se refiere pues a la validez jurídica de las leyes penales estadounidenses.

Además, como se explicó en los hechos del caso, no todos los cincuenta y dos procesos penales se encontraban en la misma etapa del pro-

17 CIDH, El Derecho a la Información sobre la Asistencia Consular. Opinión Consultiva OC-16/99 del 1o. de octubre de 1999, serie A, núm. 16, para. 117.

18 Case Concerning Avena and Other Mexican Nationals (Mexico vs. United States of America), op. cit., nota 4, para. 122. 
cedimiento; mientras había algunos casos en los que aún quedaban recursos por interponer, en otros, todos los recursos disponibles habían sido agotados ya.

Por los motivos arriba descritos, la Corte Internacional de Justicia llegó a la conclusión de que la reparación adecuada en el caso Avena sería que las cortes locales estadounidenses otorgasen la revisión y reconsideración de los cincuenta y dos casos en cuestión, a fin de analizar y determinar si efectivamente la falta de notificación consular impidió la interposición de recursos sustanciales en favor del detenido que pudiesen implicar la conmutación de la pena capital. ${ }^{19}$

Respecto de la revisión y reconsideración ordenadas por la Corte, ésta aclaró que debe ser efectiva, lo cual implica que se haga un examen exhaustivo de los casos - es decir, la revisión y reconsideración abarcan tanto la condena como la sentencia - tomando en consideración las violaciones de los derechos contenidos en la Convención de Viena, así como el posible perjuicio que dichas violaciones pudieron causar. ${ }^{20}$

Es imperativo subrayar que el hecho de que las cortes estadounidenses otorguen la revisión y reconsideración de los casos de los mexicanos sentenciados a muerte cubiertos por el paraguas del fallo Avena, de ninguna manera implica que el resultado de dicha revisión y reconsideración sea la conmutación de la pena de muerte por cadena perpetua. Es decir, si después de revisar y reconsiderar los casos de los cincuenta y un mexicanos, las cortes locales encuentran que no hay un perjuicio sustancial causado a los detenidos, aun existiendo la violación al artículo 36 de la Convención de Viena sobre Relaciones Consulares, la sentencia que ya ha sido dictada quedaría firme.

Si bien la Corte Internacional de Justicia ordenó en su resolutivo 9 que los Estados Unidos se encuentran obligados a revisar y reconsiderar, "a través de los medios de su propia elección", los procesos penales de los mexicanos condenados a pena de muerte, ello no significa una carta blanca para las cortes estadounidenses respecto a la forma y contenido que debe revestir dicha revisión y reconsideración.

La Corte no llegó a determinar, como sí lo hizo la Corte Interamericana de Derechos Humanos, que los derechos consagrados en el artículo 36 de la Convención de Viena codificasen derechos humanos. Sin em- 
bargo, sí reconoció que dichos derechos están vinculados con el debido proceso del detenido. En este sentido, determinó que un elemento crucial es que la revisión y reconsideración ordenadas deben consistir, en consecuencia, en la existencia de un proceso que garantice que se sopesen en su totalidad las violaciones al tratado cometidas, así como su posible perjuicio, sin importar el resultado de dicha revisión o reconsideración. ${ }^{21}$

Al respecto, dejó muy en claro que la solicitud de clemencia no constituye un recurso que deba ser agotado como parte de esa obligación de reparar y reconsiderar. En efecto, Estados Unidos ha incorporado el recurso de clemencia a sus procesos penales como una forma de asegurar la equidad en los casos de pena capital. No obstante lo anterior, la clemencia es un recurso administrativo y no judicial, pues su otorgamiento depende del Poder Ejecutivo. Por ello, la Corte encontró que la solicitud de clemencia no cumple con los estándares de efectividad que deben ser cubiertos al momento de revisar y reconsiderar los casos. ${ }^{22}$

Al margen de la obligación impuesta por la Corte en el sentido de otorgar una efectiva revisión y reconsideración de los casos, el máximo tribunal mundial impuso una segunda obligación a los Estados Unidos de no poca monta: el otorgamiento a México de garantías de no repetición. ${ }^{23}$ Esta forma de reparación había sido otorgada ya en favor de Alemania en el caso LaGrand. ${ }^{24}$

Esta obligación, como observaremos más adelante, adquiere mayor relevancia frente a los hechos que se sucedieron con posterioridad al fallo Avena y, en particular, en el caso del señor José Ernesto Medellín.

\section{SENTENCIA MEDELLÍN VS. TEXAS}

Decíamos ya en la introducción que el mexicano José Ernesto Medellín Rojas interpuso un recurso de habeas corpus ante la Corte Criminal de Apelaciones de Texas haciendo valer su derecho a reconsiderar y revisar su caso, habiéndose publicado el fallo de la Corte Internacional de Justicia en marzo de 2004. Texas rechazó dicha acción argumentando

21 Ibidem, para. 139.

22 Ibidem, paras. 142 y 143.

23 Ibidem, para. 150.

24 LaGrand (Germany vs. United States of America), Judgment, ICJ Rep. 2001, para. 120 . 
que la interposición del mismo constituía un "abuso del recurso" y que, con base en la doctrina de la preclusión procesal, ya había pasado el momento procesal oportuno para hacer valer sus derechos derivados de la Convención de Viena sobre Relaciones Consulares.

Así fue como, por medio del recurso de certiorari, el caso llegó por segunda ocasión a la Suprema Corte de Justicia de los Estados Unidos. Dos cuestiones tenían que ser respondidas en dicho recurso: primero, ¿es el fallo Avena directamente ejecutable como ley doméstica en una corte estatal de los Estados Unidos?, y segundo, ¿puede el memorando del presidente Bush, de forma independiente, requerir a los estados otorgar la revisión y reconsideración en favor de los cincuenta y un mexicanos nombrados en el fallo Avena, sin necesidad de observar la doctrina de la preclusión procesal? ${ }^{25}$

La Suprema Corte respondió de forma negativa ambas cuestiones, decidiendo así que ni el fallo Avena ni el "Memorando Bush" constituyen una ley federal directamente ejecutable ante las cortes estadounidenses. Dicho de otra manera, la revisión y reconsideración ordenada en el fallo Avena no puede ser concedida. Lo anterior sólo puede revertirse por medio de una legislación de implementación que permita que se ejecute el fallo de la Corte Internacional de Justicia a nivel interno.

A continuación se exponen las principales premisas utilizadas por la Suprema Corte en esta sentencia, que, desde nuestro punto de vista, demerita años de diplomacia en la construcción del complejo enramado que conforma la normativa internacional.

Respecto de la segunda cuestión, relativa a la facultad del presidente Bush para ordenar la ejecución de un fallo de la Corte Internacional de Justicia en las cortes locales, no diremos mucho; consideramos que éste es un tema que cae en el ámbito estricto del derecho estadounidense - en particular, de derecho constitucional-

Ahora, respecto de la primera cuestión, relativa a la posibilidad de ejecutar directamente el fallo Avena en cortes estadounidenses, la Suprema Corte llegó a la siguiente conclusión: si bien un tratado puede constituir un compromiso internacional, éste no es jurídicamente vinculante a menos que el Congreso haya legislado para permitir su implementación, o bien si el tratado mismo establece que se trata de un instrumento autoejecutable y que se haya ratificado bajo esta premisa. 
Al abordar este punto, la Suprema Corte ofrece varios argumentos. Comienza por reconocer el hecho de que el fallo Avena constituye una obligación internacional respecto de los Estados Unidos. No obstante, dice la Corte, no todas las obligaciones internacionales se convierten automáticamente en leyes federales que puedan ser ejecutadas en las cortes locales. ${ }^{26}$ De ahí la necesidad de estudiar la "calidad" jurídica del fallo Avena.

Se aborda entonces la diferencia entre un tratado autoejecutable y uno que no lo es. En suma, dice la Corte, mientras que los tratados pueden contener compromisos internacionales, éstos no se convierten en una ley doméstica sino hasta que el Congreso cree una ley de implementación o si el tratado mismo establece que se trata de un instrumento autoejecutable y que se haya ratificado bajo esta premisa. ${ }^{27}$

La Suprema Corte, al aterrizar estos razonamientos al caso concreto, se ve en la necesidad de determinar si el Protocolo opcional a la Convención de Viena sobre Relaciones Consulares, la Carta de las Naciones Unidas y el Estatuto de la Corte Internacional de Justicia son efectivamente tratados autoejecutables. Dice la Corte: dado que ninguno de estos tratados crea leyes federales que sean vinculantes en ausencia de una ley de implementación, y dado que es incuestionable el hecho de que tales leyes de implementación no existen, se concluye que el fallo Avena no es automáticamente vinculante a nivel interno. ${ }^{28}$

El argumento, al parecer, busca una justificación en la interpretación de los tratados internacionales antes mencionados. En opinión de la Suprema Corte, la interpretación comienza con el texto mismo del instrumento internacional en cuestión y se extiende a la negociación y a los travaux préparatoire del mismo - lo cual no presenta mayor problema-.

Respecto del artículo 1o. del Protocolo opcional, el cual otorga jurisdicción a la Corte Internacional de Justicia para conocer de aquellos casos en los que exista una disputa respecto de la aplicación o interpretación de la Convención de Viena sobre Relaciones Consulares, la Corte sostiene que hay una clara diferencia entre someter un caso a la jurisdicción de un tribunal, por un lado, y obligarse a aceptar sus fallos como

27 Idem.

28 Ibidem, p. 10. 
vinculantes, por el otro. ${ }^{29}$ Además — sigue - el Protocolo nada dice respecto al efecto que debe tener una decisión de la Corte Internacional de Justicia y no obliga, por sí mismo, a los Estados signatarios a cumplir con dicho fallo. Igualmente, el Protocolo es omiso respecto a mecanismos de ejecución. ${ }^{30}$

Este razonamiento se complementa, en opinión de la Suprema Corte, con el análisis del artículo 94 de la Carta de las Naciones Unidas. En este punto se vale del posicionamiento que hubiese hecho en su momento la administración de los Estados Unidos, que consiste en que la frase undertakes to comply (en español, "se compromete a cumplir") no implica el reconocimiento de que las decisiones de la Corte Internacional de Justicia vayan a tener un efecto vinculante inmediato en las cortes de los Estados miembros de las Naciones Unidas, sino que tan sólo expresa un compromiso por parte de los Estados miembros para tomar acciones futuras a través de sus actores políticos a fin de dar cumplimiento a la obligación impuesta. ${ }^{31}$

Finalmente, la Suprema Corte estima que, toda vez que la Carta de las Naciones Unidas establece un mecanismo diplomático para la ejecución de los fallos de la Corte Internacional de Justicia — esto es, a través de la acción del Consejo de Seguridad-, se hace así evidente que la intención detrás del artículo 94 de la Carta no es el que los fallos de la Corte sean automáticamente ejecutables en cortes locales. ${ }^{32}$

El siguiente planteamiento que hace la Suprema Corte para sostener, desde su punto de vista, que el fallo Avena no concede derechos que puedan hacerse valer ante las cortes locales es muy simple: ultimadamente, dice la Corte, el principal propósito de la Corte Internacional de Justicia es servir de árbitro particular en las disputas entre naciones; la Corte Internacional de Justicia no puede atender peticiones de individuos. Más aún — sigue-, el artículo 59 del Estatuto establece que el carácter obligatorio de las decisiones de la Corte se limita a las partes en el litigio. De tal suerte que, concluye, como el señor Medellín es un individuo, éste no es parte del litigio del caso Avena, por lo que cualquier obligación de cumplimiento que derive del fallo en cuestión implicaría la generación

29 Ibidem, p. 11.

30 Idem.

31 Ibidem, p. 12.

32 Ibidem, p. 13. 
de derechos de los que sólo México es titular y se puede beneficiar, no el señor Medellín. ${ }^{33}$

Hemos de aclarar que este razonamiento de la Suprema Corte constituye un argumento alternativo, pues de no ser así ella misma estaría reconociendo la obligatoriedad del fallo Avena en virtud del Estatuto de la Corte, cosa totalmente contradictoria con su primer argumento.

Para dar por concluida en definitiva la discusión sobre la obligatoriedad del fallo Avena, la Suprema Corte sostuvo que los Estados Unidos deben dar cumplimiento a las disposiciones de un tratado del que son parte, siempre y cuando éstas no sean contrarias a su Constitución. ${ }^{34}$

Vale la pena hacer notar un elemento esencial para la entera comprensión de las consecuencias que tiene el fallo Medellín vs. Texas. Al exponer todos los argumentos que hemos comentado, la Suprema Corte de los Estados Unidos dejó en claro una cosa: la Carta de las Naciones Unidas (dejemos de lado por un momento a los demás tratados internacionales involucrados) no es un tratado autoejecutable y, por lo tanto, sus normas no podrán ser aplicadas en los Estados Unidos, salvo que exista una ley de implementación que así lo permita. Desde nuestro punto de vista tal aseveración es muy grave, pues contraría al orden internacional e impacta a la comunidad internacional en su conjunto al atacar de manera directa el objeto y fin de la Carta, así como los principios y propósitos mismos de la ONU.

\section{SOLICITUD DE INTERPRETACIÓN DEL FALLO AVENA}

Ante la sentencia de la Suprema Corte de los Estados Unidos en el caso Medellín vs. Texas, el gobierno de México decidió actuar pro activamente en defensa del fallo Avena y, en consecuencia, en defensa de la misma Corte Internacional de Justicia. De tal suerte que, confiando en el peso legal de los fallos y la calidad de los mismos, México decidió volver al máximo tribunal internacional.

33 Medellín vs. Texas, 128 S. Ct. 1346, op. cit., nota 10, pp. 15 y 16.

34 Ibidem, p. 24. 
El 5 de junio de 2008 México presentó una solicitud de interpretación del fallo Avena de $2004 .{ }^{35} \mathrm{El}$ suscrito tuvo la oportunidad y el honor de formar parte del equipo legal de México ante la Corte Internacional de Justicia en este nuevo procedimiento. Si bien esta experiencia ha sido inmensamente interesante, formativa y enriquecedora, dado que para el momento en el que se ha elaborado el presente escrito el litigio ante la Corte sigue abierto, y dado que el espíritu del presente trabajo consiste en realizar un análisis crítico desde una óptica estrictamente académica, omitiremos aquí detalles sobre la estrategia jurídica utilizada o sobre el procedimiento mismo. Aprovechemos esta acotación para reiterar también que todas las opiniones reflejadas constituyen exclusivamente la opinión personal del autor.

Me limitaré entonces, a continuación, a resaltar los elementos jurídicos que son públicos, relativos al procedimiento ante la Corte Internacional de Justicia.

El fundamento legal que sustenta la presentación de esta solicitud se encuentra en el artículo 60 del Estatuto de la Corte, el cual dice que "el fallo será definitivo e inapelable. En caso de desacuerdo sobre el sentido o alcance del fallo, la Corte lo interpretará a solicitud de cualquiera de las partes". ${ }^{36}$

México argumenta en su solicitud que el elemento principal para activar la aplicación del artículo 60 se ha perfeccionado: la existencia de una disputa entre las partes respecto al alcance y sentido del fallo Avena. La Corte Permanente de Justicia Internacional, al interpretar su fallo en el caso Factory at Chorzów, asentó que es suficiente que los dos gobiernos involucrados sostengan puntos de vista opuestos respecto del sentido y alcance de un fallo para determinar la existencia de una disputa. ${ }^{37}$

Desde el punto de vista de México - con el cual coincidimos plenamente-, la sentencia Medellín vs. Texas, así como la actitud de la administración estadounidense frente a la misma, reflejan la idea subyacente de que el fallo Avena, en particular el párrafo operativo 153(9), contiene,

35 Request for Interpretation of the Judgment of 31 March 2004 in the Case Concerning Avena and Other Mexican Nationals (Mexico vs. United States of America) 2008, en http://www.icj-cij.org/docket.

36 Estatuto de la Corte Internacional de Justicia, artículo 60.

37 Interpretation of Judgments núms. 7 and 8 (The Chorzów Factory) (Germany vs. Poland), Judgment of 16 December 1927, PCIJ Rep, series A, núm. 13, 1927, p. 11. 
para los Estados Unidos, una obligación de medios y no de resultado. ${ }^{38}$ Esto en virtud de que Estados Unidos justifica que si bien no se ha concedido la revisión y reconsideración de los cincuenta y un casos contenidos en Avena, ello no significa que se haya incumplido el fallo, pues el problema radica en la falta de aplicabilidad del mismo en el orden interno estadounidense y no en la voluntad del gobierno - recordemos lo que dice la Suprema Corte-.

Por otro lado, la existencia del "Memorando Bush" podría sugerir que el gobierno de los Estados Unidos, a través de su jefe de Estado, ha hecho lo necesario a fin de dar cumplimiento al fallo Avena, mientras que tanto la Corte Criminal de Apelaciones de Texas como la Suprema Corte de Justicia se niegan a ello. En consecuencia, se podría argumentar, equivocadamente, que la actitud de Texas y de la Suprema Corte no debe ser atribuible a los Estados Unidos en el sentido de reflejar su postura en el plano internacional sobre este tema. Nosotros sostenemos que éste sería un argumento equivocado en virtud de las reglas de responsabilidad internacional que han sido codificadas por la Comisión de Derecho Internacional.

Cabe mencionar que ésta no es la primera ocasión en la que la Corte Internacional de Justicia recibe una solicitud de interpretación de un fa$110 .{ }^{39}$ Sin embargo, sí es la primera vez en que, acompañando a la solicitud de interpretación, se le pide también a la Corte el otorgamiento de medidas provisionales. Lo anterior se hizo en virtud de la inminente ejecución de José Ernesto Medellín Rojas y de otros cuatro mexicanos (César Roberto Fierro Reyna, Rubén Ramírez Cárdenas, Humberto Leal García y Roberto Moreno Ramos), las cuales se llevarían a cabo sin que

38 Request for Interpretation of the Judgment of 31 March 2004 in the Case Concerning Avena and Other Mexican Nationals (Mexico vs. United States of America), 2008, aplication, p. 14, para. 52.

39 Véase Request for Interpretation of the Judgment of 11 June 1998 in the Case Concerning the Land and Maritime Boundary between Cameroon and Nigeria (Cameroon vs. Nigeria), 1999; Application for Revision and Interpretation of the Judgment of 24 February 1982 in the Case Concerning the Continental Shelf (Tunisia vs. Libyan Arab Jamahiriya), 1984; Request for Interpretation of the Judgment of 20 November 1950 in the Asylum Case (Colombia vs. Peru), 1950. 
estos cinco mexicanos hubiesen recibido la revisión y reconsideración concedida en el fallo Avena. ${ }^{40}$

Como habíamos mencionado, el 5 de mayo de 2008 Texas fijó como fecha de ejecución para José Ernesto Medellín el 5 de agosto de ese mismo año. Esto provocó que la Corte Internacional de Justicia fijara fechas de audiencia para escuchar los argumentos de las partes al respecto los días 19 y 20 de junio anteriores a la fecha de ejecución de Medellín. Posteriormente, el 16 de julio de 2008, con siete votos a favor y cinco en contra, la Corte emitió su ordenanza sobre medidas provisionales, las cuales fueron concedidas en favor de México.

En dicha ordenanza, la Corte obligó a los Estados Unidos a tomar todas las medidas necesarias para asegurar que los cinco mexicanos arriba mencionados no fuesen ejecutados hasta en tanto la Corte resolviese sobre el fondo de la solicitud de interpretación presentada por México, a menos que, y en tanto que, se llevara a cabo la revisión y reconsideración de sus casos de conformidad con lo establecido en los párrafos 138 a 141 del fallo Avena. ${ }^{41}$

Al tiempo que la Corte ordenó lo anterior, también dejó en claro que Estados Unidos incurriría en responsabilidad internacional si alguno de los mexicanos contenidos en el fallo Avena fuese ejecutado sin haber recibido la revisión y reconsideración de su caso. ${ }^{42}$

El mismo día en que la Corte concedió medidas provisionales en favor de México, Robert Black, portavoz del gobernador de Texas, Rick Perry, anunció que "Texas no está sujeto a tribunales extranjeros", confirmando así que la decisión de ejecutar a los mexicanos condenados a la pena de muerte en ese estado de la Unión quedaba firme. ${ }^{43}$

En los días que siguieron a la publicación de la ordenanza de la Corte y hasta el lunes 4 de agosto, un sinnúmero de cartas, involucrando a

40 Request for Interpretation of the Judgment of 31 March 2004 in the Case Concerning Avena and Other Mexican nationals (Mexico vs. United States of America). Request for the Indication of Provisional Measures of Protection Submitted by the Government of the United Mexican States, 5 June 2008, en http://www.icj-cij.org/docket/files/139/145 80.pdf.

41 Request for Interpretation of the Judgment of 31 March 2004 in the Case Concerning Avena and Other Mexican Nationals (Mexico vs. United States of America). Request for the Indication of Provisional Measures, Order of 16 July 2008, p. 19, para. 80.

42 Ibidem, p. 18, para. 76.

43 "Rechaza Texas orden de CIJ; ejecutará a mexicanos", El Universal, 16 de julio de 2008, http://www.eluniversal.com.mx/notas/523018.html. 
una gran cantidad de actores nacionales e internacionales, fueron enviadas al gobierno de Texas solicitando la clemencia en favor de José Ernesto Medellín. El objetivo era obtener la suspensión de la ejecución, planeada para el 5 de agosto, a fin de que hubiese tiempo para llevar a cabo la revisión y reconsideración de su caso, tal y como lo había ordenado la Corte Internacional de Justicia. Precisamente el 4 de agosto, la Junta de Perdones y Libertades Condicionales de Texas (Board of Pardons and Paroles) emitió su recomendación al gobernador de Texas, en la que rechazaba la solicitud de clemencia. ${ }^{44}$ Ese mismo lunes, Medellín fue trasladado a la prisión de Huntsville, en donde sería ejecutado al día siguiente en punto de las 18:00 horas.

El martes 5 de agosto, el gobernador Perry, pocos minutos después de las 17:00 horas, rechazó en definitiva la solicitud de clemencia. Sin embargo, la ejecución no se llevó a cabo a las 18:00 horas como estaba planeado; el lunes de esa semana los abogados de Medellín interpusieron un último recurso ante la Suprema Corte de los Estados Unidos solicitando la suspensión de la ejecución bajo el argumento de que se le tenía que otorgar tiempo suficiente tanto al Congreso estadounidense como a la legislatura local de Texas para determinar, en caso de que se hubiesen causado violaciones a la Convención de Viena sobre Relaciones Consulares, la forma en la que éstas debían ser reparadas, de conformidad con lo ordenado por la Corte Internacional de Justicia. ${ }^{45}$

Las autoridades tejanas, en deferencia a la Suprema Corte, esperaron a que ésta emitiese su decisión sobre el recurso interpuesto. En una cerrada votación de cinco votos a favor y cuatro en contra, el recurso fue rechazado.

José Ernesto Medellín fue ejecutado en punto de las 21:57 horas del martes 5 de agosto de 2008, en una clara y desafiante violación de la ordenanza de medidas provisionales emitida por la Corte Internacional de Justicia. ${ }^{46}$ Estados Unidos incurría por tercera vez en su historia en la misma falta.

44 "Rechaza clemencia Junta de Perdones de Texas para Medellín", La Jornada, 4 de agosto de 2008, http://www.jornada.unam.mx/ultimas/2008/08/04/niega-junta-de-per dones-de-texas-clemencia-para-medellin.

45 In Re José Ernesto Medellín (Per Curiam), 554 S. Ct. (US 2008) (núm. 08-5574).

46 "Ejecutan a Medellín en Texas", La Jornada, 5 de agosto de 2008, http://www. jornada.unam.mx/ultimas/2008/08/05/texas-preparado-para-ejecutar-a-mexicano-mede llin-pese-a-pedido-de-corte-internacional. 


\section{REFLEXIONES FINALES SOBRE LA SENTENCIA \\ MEDELLÍN VS. TEXAS Y LA EJECUCIÓN DE JOSÉ ERNESTO MEDELLÍN}

Desde nuestro punto de vista, la sentencia de la Suprema Corte de los Estados Unidos en el caso Medellín vs. Texas constituye una afrenta real y directa al sistema jurídico internacional $\mathrm{y}$, en consecuencia, a la comunidad internacional; los argumentos para sostener una decisión de esta naturaleza no sólo carecen de sustento legal sino que reflejan también un alto grado de cinismo.

Las interrogantes jurídico-internacionales que se presentan en este caso son claras: ¿son vinculantes las decisiones de la Corte Internacional de Justicia? De ser así, ¿cómo lograr la ejecución y el cumplimiento de las mismas ante la renuencia de un Estado a cumplir?

Notamos que el punto central de la discusión versa sobre el derecho de los tratados: su obligatoriedad, su implementación y su cumplimiento. Paul Reuter escribe que "la esencia misma del derecho de los tratados incluye los otros principios básicos del derecho internacional público". ${ }^{47}$ Estamos totalmente de acuerdo, y un elemento clave para determinar la obligatoriedad de los tratados que simplemente no fue tomado en consideración por la Suprema Corte es el principio de derecho internacional pacta sunt servanda: "Todo tratado en vigor obliga a las partes y debe ser cumplido por ellas de buena fe". ${ }^{48}$ Es claro cómo el principio citado tiene un carácter imperativo al usar la palabra obliga, haciendo referencia al compromiso que ha sido adquirido por las partes.

Por otro lado, el artículo 31 de la Convención de Viena sobre el Derecho de los Tratados de 1969 establece como regla general que la interpretación de un instrumento internacional debe llevarse a cabo, en primer lugar, de buena fe y "conforme al sentido corriente que haya de atribuirse a los términos del tratado en el contexto de éstos y teniendo en cuenta su objeto y fin". ${ }^{49}$

La aplicación de este criterio a las normas contenidas en los tratados analizados por la Suprema Corte —el Protocolo opcional, la Carta de la

47 Reuter, Paul, Introducción al derecho de los tratados, México, FCE-UNAM, 1999, p. 43.

48 Convención de Viena sobre el Derecho de los Tratados, UN Doc A/CONF/.39/29. 1155 UNTS 331. Firmada en Viena el 23 de mayo de 1969, en vigor desde el 27 de enero de 1980 , artículo 26.

49 Ibidem, artículo 31. 
ONU y el Estatuto de la Corte Internacional de Justicia- evidencia su obligatoriedad. Respecto del Protocolo opcional, el artículo 1o. dice: "Las controversias originadas por la interpretación o aplicación de la Convención se someterán obligatoriamente a la Corte Internacional de Justicia, que a este título podrá entender en ellas a instancia de cualquiera de las partes en la controversia que sea parte en el presente Protocolo". ${ }^{50}$ La versión en inglés es aún más clara en términos de la obligatoriedad de las decisiones de la Corte, pues dice "disputes arising out of the interpretation or application of the Convention shall lie within the compulsory jurisdiction of the International Court of Justice" (énfasis agregado).

El artículo 1o. del Protocolo opcional no sólo remite los casos que surjan de la aplicación e interpretación de la Convención de Viena sobre Relaciones Consulares a la Corte Internacional de Justicia, sino que las partes, al llevar un caso con base en este artículo a la Corte, se someten a la jurisdicción obligatoria de ésta. La jurisdicción obligatoria (compulsory jurisdiction) de la Corte está codificada en el artículo 36(2) de su Estatuto. La aceptación de este tipo de jurisdicción implica el sometimiento de un Estado a las decisiones de la Corte, reconociendo así su validez y su carácter vinculante.

Vayamos un paso más adelante, como lo sugiere el mismo artículo 31 de la Convención de Viena sobre el Derecho de los Tratados: ¿la interpretación que sugerimos sobre la obligatoriedad de las sentencias de la Corte Internacional de Justicia es congruente con el objeto y fin de los tratados que la contemplan? La respuesta, sin lugar a dudas, es un rotundo sí.

Los motivos son muy sencillos. Tomemos de nueva cuenta, y en primer lugar, al artículo 1o. del Protocolo opcional. Basta releer con atención el nombre del tratado que está siendo analizado para encontrar el objeto del mismo: Protocolo de Firma Facultativa sobre Jurisdicción Obligatoria para la Solución de Controversias. ¿Para qué habrían de firmar los Estados este protocolo si no estuviesen convencidos de que, de darse el caso, sus disputas serán sometidas a una Corte a fin de que su decisión solucione la controversia en cuestión de manera definitiva? ¿Acaso la definitividad de una sentencia de la Corte no radica en su obligatoriedad? Por supuesto que sí.

50 Protocolo de Firma Facultativa sobre Jurisdicción Obligatoria para la Solución de Controversias. UNTS 500, en vigor desde el 18 de abril de 1961. 
¿Qué hay del artículo 94 de la Carta de las Naciones Unidas? Dicha disposición establece claramente que "cada miembro de las Naciones Unidas se compromete a cumplir la decisión de la Corte Internacional de Justicia en todo litigio en que sea parte". ${ }^{51}$ Cabe destacar que, en opinión de Alain Pillepich, la palabra "decisión" utilizada en el artículo 94 implica que el pronunciamiento de la Corte ha dado una respuesta definitiva al litigio. ${ }^{52} \mathrm{Si}$ el objeto y fin del establecimiento de la Corte Internacional, y de esta disposición en particular, es que se cumplan sus decisiones a fin de solucionar definitivamente las controversias jurídicas que puedan surgir entre los Estados de la ONU, ¿no es necesario entender que las partes en un litigio ante este máximo tribunal están obligadas a cumplir con sus fallos? Una vez más, nosotros consideramos que esto es así.

La interpretación propuesta en el párrafo anterior no es nueva ni arbitraria; todo lo contrario. En la Carta de las Naciones Unidas comentada, que fue editada bajo el cuidado del juez de la Corte Internacional de Justicia Bruno Simma, los profesores Hermann Mosler y Karin Oellers-Frahm anotaron con toda claridad que las partes de una disputa, que sean miembros de la ONU, están obligados bajo el artículo 94(1) de la Carta a cumplir con las decisiones de la Corte, y que esta misma obligación es impuesta a todos aquellos Estados, miembros o no de la ONU, que han aceptado la jurisdicción obligatoria de la Corte a través de declaraciones $^{53}$ - aquí podemos deducir que esta misma condición se mantiene al tratarse de la aceptación de la jurisdicción obligatoria a través de la firma de tratados que contienen una cláusula en estos términos-.

Finalmente, respecto de la interpretación que debe hacerse del Estatuto de la Corte, éste, en su artículo 59, establece que "la decisión de la Corte no es obligatoria sino para las partes en litigio y respecto del caso que ha sido decidido". ${ }^{54}$ Este artículo se encuentra correlacionado armónicamente con el artículo 94 de la Carta. Ante este escenario jurídico, la obligatoriedad de los fallos es clara.

51 Carta de las Naciones Unidas, artículo 94.1.

52 Pillepich, Alain, "Article 94", en Cot, Jean-Pierre y Pellet, Alain (dirs.), La Charte des Nations Unies, 3a. ed., París, Económica, p. 1994, para. 15.

53 Mosler, Hermann y Oellers-Frahm, Karin, “Article 94”, en Simma, Bruno (ed.), The Charter of the United Nations, a commentary, 2a. ed., Oxford, Oxford University Press, 2002, vol. II, p. 1175, para. 3.

54 Estatuto de la Corte Internacional de Justicia, artículo 59. 
Respecto al argumento de la Suprema Corte de que Medellín, en su carácter individual, no adquirió derechos con el fallo Avena, el grave error que subyace es que implica la omisión de un derecho inherente a los Estados, y a partir del cual se gesta toda la controversia que tenemos sobre la mesa: el derecho de ejercer protección diplomática en favor de sus nacionales. Este derecho fue reconocido por la Corte Permanente de Justicia Internacional como un principio de derecho internacional en el caso Mavrommatis Palestine Concessions. Ahí se determinó que un Estado tiene el derecho de proteger a sus individuos cuando éstos han sido afectados por actos contrarios al derecho internacional cometidos por otro Estado, del cual no han podido obtener una satisfacción por las vías ordinarias. ${ }^{55}$ Además del caso Avena, la protección diplomática ha sido central en los casos de Nottebohm, ${ }^{56}$ Teheran, ${ }^{57}$ Paraguay ${ }^{58}$ y LaGrand, ${ }^{59}$ ante la Corte Internacional de Justicia.

Ya se ha publicado también en este Anuario un artículo extraordinario sobre protección diplomática a cargo de la maestra Mariana Salazar Albornoz, en el que se aborda ampliamente la participación que tienen en la actualidad los individuos en el sistema jurídico internacional, así como los derechos que éstos han obtenido con el paso del tiempo. ${ }^{60}$ Resulta ocioso entonces explicar cómo opera el ejercicio de la protección diplomática. Baste afirmar, sin temor a equivocaciones, que efectivamente el fallo Avena, al ordenar a los Estados Unidos la revisión y reconsideración de los casos de cincuenta y un mexicanos condenados a pena de muerte, en realidad está concediendo derechos a favor de individuos, siendo Medellín uno de ellos. Si esto no fuese así, el derecho a la protección diplomática carecería de todo contenido y de todo sentido.

Por último, en lo que respecta al argumento de la Suprema Corte sobre la defensa del orden jurídico interno estadounidense, podemos decir

55 Mavrommatis Palestine Concessions Case (Greece vs. UK) (Jurisdiction) Judgment of August 30, 1924, PCIJ, Rep., series A, núm. 2, p. 12.

56 Nottebohm Case (Liechtenstein vs. Guatemala) (2nd. Phase) [1955] ICJ Rep 4.

57 United States Diplomatic and Consular Staff in Teheran (United States vs. Iran) (Judgment on Merits) [1980] ICJ Rep 3.

58 Vienna Convention on Consular Relations (Paraguay vs. United States of America), Provisional Measures, Order of 9 April 1998, ICJ Rep. 1998, p. 248.

59 LaGrand (Germany vs. United States of America), Judgment, ICJ Rep. 2001.

60 Salazar, Mariana, "Legal Nature and Legal Consequences of Diplomatic Protection. Contemporary Challenges", Anuario Mexicano de Derecho Internacional, México, vol. VI, 2006, pp. 377-417. 
lo siguiente: si bien reconocemos que los Estados deben asegurarse que, al firmar y ratificar un tratado internacional, éste no se contraponga a su orden interno $\mathrm{y}$, en particular, a su texto constitucional, ello no implica que las obligaciones adquiridas a partir de la norma internacional pactada carezcan de valor jurídico en tanto no se encuentren en armonía con el derecho interno. Esta regla también ha quedado asentada con toda claridad en la Convención de Viena sobre el Derecho de los Tratados, la cual dispone en su artículo 27 que "una parte no podrá invocar las disposiciones de su derecho interno como justificación del incumplimiento de un tratado". ${ }^{61}$

Así se hacen vigentes aquí las palabras de Anthony Aust cuando escribe que si se necesita una nueva ley o la modificación a una ley a fin de ejecutar las obligaciones impuestas a través de un tratado, el Estado que negocia deberá asegurarse de que esto se realice, por lo menos, en el lapso de tiempo que transcurrirá antes de que el tratado entre en vigor; de no ser así, no sólo el Estado estará en riesgo de violar sus obligaciones contractuales sino que podrá incurrir en responsabilidad internacional frente a otro Estado parte si como resultado de esta situación el otro Estado, o un nacional del otro Estado, se ven dañados. ${ }^{62}$ Tal es el caso.

Por otro lado, resulta innegable que la Carta de las Naciones Unidas, hoy por hoy, se toma como el marco legal de referencia para los Estados; la Carta incorpora la gran mayoría de las normas primarias de derecho internacional que deben observarse.

Sugerir, pues, que sin leyes reglamentarias los principios de derecho internacional público contenidos en la Carta carecen de fuerza en el terreno práctico no sólo raya en lo absurdo sino que resulta contradictorio ante lo que el mundo ha demostrado en los más de sesenta años de vida de la Organización de las Naciones Unidas.

Es por estos motivos que, desde nuestro punto de vista, la sentencia Medellín vs. Texas del 25 de marzo de 2008 refleja una clara reticencia por parte de los Estados Unidos a cumplir con sus obligaciones internacionales y constituye, además, un golpe duro a la confiabilidad, credibilidad y fortaleza de la Corte Internacional de Justicia.

61 Convención de Viena sobre el Derecho de los Tratados, artículo 27.

62 Cfr. Aust, Anthony, Modern Treaty Law and Practice, Cambridge, Cambridge University Press, 2000, p. 144. 
Volvamos ahora a la ejecución de Ernesto Medellín el 5 de agosto de 2008. El punto de partida, desde un enfoque jurídico, es incuestionable: los Estados están obligados a cumplir con una orden de medidas provisionales emitida por la Corte. El carácter obligatorio de las medidas provisionales implica, en primer lugar, que el incumplimiento de las mismas constituye una violación del derecho internacional con todas las consecuencias que esto conlleva. ${ }^{63} \mathrm{El}$ concepto mismo de medidas provisionales como medidas "que deben ser tomadas" significa que se trata de medidas que requieren algún tipo de respuesta por parte del Estado, ya sea a través de actos u omisiones. ${ }^{64}$

La misma Corte Internacional de Justicia dejó lo anterior muy en claro en su fallo relativo al caso LaGrand. Ante la ejecución de Walter LaGrand, la Corte explicó con puntualidad que las medidas provisionales se otorgan con base en la necesidad de salvaguardar y de evitar causar un perjuicio irreparable a los derechos de las partes en el litigio, por lo que considerar que las medidas provisionales ordenadas bajo el artículo 41 del Estatuto no son obligatorias sería contrario al objeto y fin del mismo artículo. ${ }^{65}$

La violación al derecho internacional al ejecutar a Medellín es incuestionable. Desde nuestro punto de vista, la hipótesis que se presenta ante la postura que ha mantenido Estados Unidos - en el sentido de no negar las obligaciones que le han sido impuestas por la Corte, aun cuando incumpla con ellas - ya ha sido estudiada por Constanze Schulte. Ella escribe que se puede dar el caso en el que el "deudor" reconozca la obligación impuesta, así como las peticiones que la sustentan, pero que sea dudoso si sus palabras son congruentes con las acciones realizadas. En este caso, dice, la disputa se centrará en hechos - el comportamiento real del deudor - y no versará sobre la obligatoriedad de la decisión o el alcance que resulta de dicha obligación. Si el deudor, de hecho, y a pesar de sus anuncios en contrario, no hace lo que se le requiere, estamos frente a un caso cierto de incumplimiento; más aún, si el deudor engañosa-

63 Oellers-Frahm, Karin, "Article 41", en Zimmermann, Andreas et al. (ed.), The Statute of the International Court of Justice; A Commentary, Nueva York, Oxford University Press, 2006, p. 958.

64 Schulte, Constanze, Compliance with Decisions of the International Court of Justice, Nueva York, Oxford University Press, 2004, p. 33.

65 LaGrand (Germany vs. United States of America), Judgment, cit., nota 24, p. 503, para. 102 . 
mente sostiene haber cumplido con una decisión mientras está consciente de sus acciones contrarias a ésta, podemos hablar de la existencia de un desafío "disfrazado". 66

Habremos de esperar la reacción tanto de los Estados Unidos como de la Corte Internacional de Justicia ante el incumplimiento de una orden vinculante. Es cierto que la tarea de hacer cumplir a los Estados con los fallos de la Corte no le concierne a la Corte misma; es en el Consejo de Seguridad en quien, por virtud del artículo 94(2) de la Carta, descansa esta labor. Sin embargo, el incumplimiento de un fallo de la Corte afecta su posición como el instrumento para la solución pacífica de controversias, lo que, al final del día, afecta también la habilidad de las Naciones Unidas para alcanzar uno de sus principios y propósitos más importantes. ${ }^{67}$

Respecto a la posibilidad de que el estado de Texas haga que sean los Estados Unidos quienes incurran en responsabilidad internacional, podemos decir lo siguiente: en 2001, la Comisión de Derecho Internacional concluyó sus trabajos de consolidación del "Proyecto de artículos sobre responsabilidad internacional de los Estados", 68 el cual fue presentado a la Asamblea General en su 56o. periodo de sesiones. Dicho proyecto de artículos, si bien no constituye una convención que sea vinculante para los Estados, sí codifica, en su mayoría, tanto reglas de costumbre como principios generales de derecho internacional que le dan valor jurídico. ${ }^{69}$ El artículo 4o. de este proyecto establece lo siguiente:

1. Se considerará hecho del Estado según el derecho internacional el comportamiento de todo órgano del Estado, ya sea que ejerza funciones legislativas, ejecutivas, judiciales o de otra índole, cualquiera que sea su posición en la organización del Estado y tanto si pertenece al gobierno central como a una división territorial del Estado.

66 Schulte, Constanze, op. cit., nota 64, pp. 34 y 35.

67 Amr, Mohamed Sameh, The Role of the International Court of Justice as the Principal Judicial Organ of the United Nations, La Haya, Kluwer Law Internacional, 2003, p. 387.

68 Comisión de Derecho Internacional, "Responsibility of States for Internationally Wrongful Acts", en Report of the International Law Commission on the Work of its 53rd. Session, 23 de abril-1 de junio y 2 de julio-10 de agosto de 2001, UN Doc A/56/10.

69 Véase Case Concerning the Application of the Convention on the Prevention and Punishment of the Crime of Genocide (Bosnia and Herzegovina vs. Serbia and Montenegro) (Judgment) [2007] ICJ Rep 1, 138, para. 385. 
2. Se entenderá que órgano incluye toda persona o entidad que tenga esa condición según el derecho interno del Estado. ${ }^{70}$

Bajo este supuesto queda claro que tanto el sistema judicial de Texas como el de la Unión caen dentro del paraguas del artículo $4.1 \mathrm{y}$, por lo tanto, sus acciones pueden ser entendidas como actos del Estado para fines de responsabilidad internacional; más aún cuando la decisión de la Suprema Corte tiene la última palabra sobre un caso en particular y es vinculante, en consecuencia, para todos los actores involucrados del Estado en cuestión.

\section{CONCLUSIÓN}

Como habrá podido advertir el lector, el caso que hemos abordado en este ensayo no se refiere a la discusión propia de la filosofía del derecho respecto a la relación que guarda el derecho nacional y el derecho internacional ${ }^{71}$ tampoco se limita sólo a la interpretación y aplicación, en sentido estricto, de la ley internacional. El caso de José Ernesto Medellín, con todas sus vertientes jurídicas, tanto en el plano interno como en el internacional, tiene un impacto significativo en el contenido que se le debe dar hoy en día a la expresión "Estado de derecho".

En un solo caso se ponen en juego la vigencia de las normas internacionales, el prestigio de la Corte Internacional de Justicia así como de otros actores internacionales, el valor de la palabra de un Estado y, por si fuera poco, la vida de un ser humano - aun cuando la litis no verse sobre la pena de muerte per se-.

Dice el juez Stevens — y dice bien — en su opinión disidente a la decisión de la Suprema Corte de negar la suspensión de la ejecución de Medellín: "Al poner en la balanza el honor de la nación frente al asumir la modesta carga que conlleva retrasar por un corto periodo de tiempo [la ejecución] para asegurarnos de que nos es imposible evitar la violación

70 Comisión de Derecho Internacional, "Responsibility of States for Internationally Wrongful Acts", op. cit., nota 68, p. 84.

$71 \mathrm{Si}$ al lector le interesa este tema, le sugerimos, a modo de introducción al mismo, la siguiente lectura: Kelsen, Hans, Principles of International Law, Nueva York, Rinehart \& Company, 1959, pp. 401-447. 
[a la Convención de Viena sobre Relaciones Consulares] me convenzo de la necesidad de otorgar la suspensión". ${ }^{72}$

La comunidad internacional estuvo al pendiente de los avances del caso, probando así que el desenlace del litigio no le es ajeno. Y, ¿cómo habría de serle ajeno cuando lo que está en riesgo es la fuerza y la eficacia de los recursos de los que puede valerse un Estado en la protección de sus nacionales?

Por lo pronto, México deberá asumir la responsabilidad de continuar con esta batalla por todos los medios jurídicos, políticos y diplomáticos que estén a su alcance. Estados Unidos, por su parte, deberá asumir la responsabilidad de sus acciones y responder en consecuencia.

Frente a este escenario, la inclusión del tema "El Estado de derecho en los planos nacional e internacional" en la agenda de la Sexta Comisión, cobra especial relevancia. El 11 de mayo de 2006, los gobiernos de México y Liechtenstein, conjuntamente, solicitaron a la Asamblea General de la ONU la inclusión de dicho tema, ${ }^{73}$ propuesta que fue aceptada por este órgano. Como consecuencia de dicha propuesta, la Asamblea General emitió su resolución A/Res/61/39, del 4 de diciembre de 2006, mediante la cual se estableció que este tema se debatiría en su 62o. periodo de sesiones.

Así pues, en el sexagésimo segundo periodo de sesiones de la Asamblea General, México, a recomendación de la Consultoría Jurídica de la Cancillería, introdujo dos temas a la mesa de debates de la Sexta Comisión: 1) la implementación de tratados en el marco jurídico nacional, y 2) el papel de los tribunales internacionales en el fortalecimiento del Estado de derecho. ${ }^{74}$ Ambos fueron muy bien recibidos. Sin embargo, dada la gran cantidad de temas e intereses de las delegaciones, la Sexta Comisión no logró elegir por consenso uno o dos subtemas de estudio. Éste parece ser un buen momento para redoblar esfuerzos y promover estos subtemas como ejes prioritarios del Estado de derecho en el plano internacional.

72 In Re José Ernesto Medellín (Per Curiam), cit., nota 45, J. Stevens, Dissenting, p. 2.

73 A/Res/61/142, del 22 de mayo de 2006.

74 Intervención de la delegación de México en el tema 86 del 62o. periodo ordinario de sesiones de la Asamblea General de las Naciones Unidas, "El Estado de derecho en los planos nacional e internacional", Nueva York, 25 de octubre de 2007. Misión Permanente de México ante las Naciones Unidas, http://www.sre.gob.mx/onu/. 
Decía el ex juez presidente de la Corte Internacional de Justicia Stephen Schwebel, quien, dicho sea de paso, es oriundo de los Estados Unidos de América:

Es lo suficientemente obvio que el derecho internacional es una significativa fuerza en los asuntos de los hombres sólo en la medida en la que los hombres y sus instrumentos cumplan con la ley... La esperanza es que habrá un proyecto a largo plazo, y que en el transcurso de él, instituciones internacionales más fuertes apoyadas en un más profundo sentido de comunidad internacional se desarrollarán gradualmente. Si y cuando ese día venga, sanciones satisfactorias con las que se pueda sustentar un derecho internacional verdaderamente efectivo deberían ser tan practicables como hoy son deseables. ${ }^{75}$

Así sea.

\author{
VII. ANEXO \\ POSICIÓN DEL GOBIERNO DE MÉXICO \\ ANTE LA EJECUCIÓN EN TEXAS DEL MEXICANO \\ JOSÉ ERNESTO MEDELLÍN ROJAS
}

Comunicado de prensa 217. Martes 5 de agosto de 2008.

Secretaría de Relaciones Exteriores.

El mexicano José Ernesto Medellín Rojas fue ejecutado hoy por las autoridades de Texas, en claro desacato a la ordenanza de la Corte Internacional de Justicia (CIJ) del 16 de julio de 2008, de tomar todas las medidas necesarias para evitar su ejecución sin que se procediera a la revisión y reconsideración de su condena, como se deriva de su fallo en el caso Avena de 2004. Al momento de su detención, las autoridades de Texas nunca le informaron sobre su derecho a la protección consular, en violación a la Convención de Viena sobre Relaciones Consulares (CVRC).

El gobierno de México ha enviado una nota de protesta al Departamento de Estado de Estados Unidos por esta violación al derecho internacional, preocupado por el precedente que pueda sentar para los derechos de los connacionales que puedan ser detenidos en ese país. La Secretaría de Relaciones Exteriores rei-

75 Cfr. Schwebel, Stephen M., Justice in International Law, Cambridge University Press, 1994, pp. 598 y 607. 
tera que la importancia fundamental de este caso es el respeto al derecho al acceso a la protección que brindan nuestros consulados a los mexicanos en el exterior.

La Secretaría de Relaciones Exteriores agotó todas las instancias legales a su alcance, tanto internas como internacionales, con el fin de obtener la revisión y reconsideración del caso a la luz de la falta de notificación consular. Se anexa un recuento de las medidas adoptadas en congruencia con el indeclinable compromiso de defender los derechos de los mexicanos.

El gobierno de México continuará insistiendo en la obligación de Estados Unidos de otorgar la revisión y reconsideración de las condenas de pena de muerte de los otros nacionales mexicanos cubiertos por el fallo Avena. La Secretaría de Relaciones Exteriores reitera su compromiso con la protección consular de los ciudadanos mexicanos en el exterior.

\section{ACCIONES DEL GOBIERNO DE MÉXICO EN TORNO A ESTE CASO}

El 31 de marzo de 2004 la Corte Internacional de Justicia reconoció en el caso Avena y Otros Nacionales Mexicanos (México vs. Estados Unidos de América) que autoridades estadounidenses nunca informaron a 51 connacionales condenados a muerte en ese país sobre su derecho a que su detención fuese notificada al Consulado de México. Ello viola la Convención de Viena sobre Relaciones Consulares (CVRC), por lo que la Corte ordenó proceder a la revisión y reconsideración de los casos por la vía judicial para determinar el perjuicio causado.

El presidente George W. Bush buscó, a través de un memorando, ordenar a las cortes de los estados dar cumplimiento a dicho fallo. No obstante, la Suprema Corte de Estados Unidos concluyó en el caso Medellín contra Texas que ni el memorando ni el fallo de la CIJ tienen carácter de normas federales obligatorias para las cortes de ese país. El 31 de marzo de 2008 el gobierno de México presentó una nota diplomática al Departamento de Estado expresando su inconformidad por esta decisión.

$\mathrm{Al}$ existir un evidente desacuerdo respecto de la naturaleza de la obligación de revisar y reconsiderar las condenas capitales de los 51 connacionales, México presentó ante la CIJ el 5 de junio de 2008 una solicitud de interpretación sobre el sentido y alcance del fallo Avena. Solicitó también a la CIJ medidas provisionales a fin de evitar su ejecución y la de otros cuatro mexicanos en tanto el tribunal internacional no resolviera sobre el fondo de la solicitud de interpretación planteada por nuestro país. Éstas fueron concedidas el 16 de julio. 
El pasado 24 de julio la Comisión Interamericana de Derechos Humanos también decidió que Estados Unidos causó un perjuicio al señor Medellín, al violar los derechos que le asisten bajo la Convención de Viena sobre Relaciones Consulares.

La Embajada de México en Estados Unidos ha promovido que se presente en el Congreso de Estados Unidos una iniciativa de ley que faculte a las cortes federales de ese país para considerar estos casos. Ello ocurrió el 14 de julio pasado, a iniciativa de los legisladores demócratas por California, Howard L. Berman, presidente del Comité de Asuntos Exteriores de la Cámara de Representantes, y Zoe Lofgren. Se mantiene asimismo el seguimiento a los esfuerzos legislativos para cumplir con el fallo Avena que han sido anunciados por el senador estatal de Texas, Rodney Ellis.

El 28 de julio la Secretaría de Relaciones Exteriores envió una carta al gobernador Perry solicitándole otorgar una suspensión de la ejecución con base en la orden de medidas provisionales de la CIJ. El 31 de julio pasado, el consultor jurídico de esta Secretaría, la cónsul general de México en Austin y abogados de la defensa del señor Medellín se reunieron con funcionarios de la oficina del abogado general del estado de Texas, y el 1o. de agosto el cónsul general de México en Houston y abogados de la defensa se reunieron con la presidenta de la Junta de Perdones.

Representantes de doce países latinoamericanos (Argentina, Bolivia, Chile, Ecuador, El Salvador, Guatemala, Honduras, Brasil, Paraguay, Perú, Uruguay y Venezuela), así como del Consejo de Europa, a nombre de sus 47 miembros, y de la Unión Europea en representación de los 27 países que la integran, suscribieron cartas a la Junta de Perdones y al gobernador Perry expresando su respaldo a la petición de clemencia del connacional. En coordinación con la SRE, el 16 de julio el presidente de la Comisión Nacional de los Derechos Humanos envió una carta con el mismo propósito a la Junta de Perdones. El 31 de julio pasado, el gobernador del estado de Tamaulipas, de donde es oriundo el connacional, envió una carta a su homólogo tejano apoyando la solicitud de clemencia.

Por su parte, los abogados del señor Medellín presentaron el 15 de julio pasado una petición de clemencia ejecutiva a la Junta de Perdones y Libertad Condicional de Texas. El mismo 28 de julio interpusieron una segunda petición subsecuente de habeas corpus ante la Corte de Apelaciones Criminales de Texas, misma que fue negada el 31 de julio. Ese mismo día accedieron ante la Suprema Corte de Estados Unidos a fin de promover un recurso ulterior de revisión y suspensión de ejecución. Desafortunadamente, éste fue negado hoy. 